\title{
Replacement of the Corneal Endothelium by Melanocytes
}

\author{
J. Reimer Wolter \\ Department of Ophthalmology, University of Michigan Medical Center, Ann Arbor, \\ Michigan 48109, USA
}

\begin{abstract}
Replacement of the corneal endothelium by a monolayer of melanocytes is reported in typical association with earlier surgery and glaucoma. The melanocytes have adjusted to the new location and there are signs that they may have taken on some of the functions of the missing endothelium. The possibility of future use of planned seeding of melanocytes in cases with failing endothelium is considered.

Zusammenfassung. Ersatz des Hornhautendothels durch eine einzellige Schicht von Melanozyten wird in typischer Verbindung mit einer Vorgeschichte von einer Augenoperation und Glaukom beschrieben. Die Melanozyten haben sich der neuen Lage gut angepaßt und es finden sich Zeichen dafür, daß sie auch einige der Funktionen des fehlenden Endothels übernommen haben. Die Möglichkeit von geplanter Verpflanzung von Endothelzellen auf die Hornhauthinterfläche in Fällen mit versagendem Endothel wird besprochen.
\end{abstract}

Progress in anterior segment surgery has been difficult for the corneal endothelium. This monolayer, furthermore, tends to degenerate on its own in many eyes of older patients even without a surgical insult. Finding a cell that could be used to replace a failing corneal endothelium is, thus, a worthwhile enterprise. The first aim, of course, is to grow human endothelium in tissue culture and to seed it on Descemet's membrane when this has lost its original endothelium (Bahn et al.). The slow growth of endothelium in the adult human eye causes a basic problem with this approach. Finding another cell type with a greater growth potential to replace the corneal endothelium is another possibility. A replacement for the corneal endothelium should have the following characteris-

From the Departments of Ophthalmology and Pathology of The University of Michigan Medical Center, Ann Arbor, Michigan

Supported by: The Research To Prevent Blindness, Inc., New York, N.Y.

Offprint requests to: J. Reimer Wolter 
tics: it should readily proliferative to form a monolayer. It should be relatively clear in an optical sense, it should be able to get along with Descemet's membrane, and it should work as a pump and maintain a state of dehydration in the corneal stroma.

It is an old rule that nature experiments for us and that we can get directions for our research by observing the ways of nature. It is for this reason that proliferation of melanocytes on the posterior corneal surface will be demonstrated and discussed in the following from a new viewpoint.

\section{Case Report}

This black male was first seen in 1973 at the age of 61 years. Cataract surgery in his right eye had been done elsewhere 8 years earlier and it had failed. The patient had lost almost all vision and developed glaucoma that could be controlled with eye drops. The patient came because of pain in the right eye. Our first examination revealed in the right eye vision of counts fingers in two feet, diffusely gray corneal scarring, and an intraocular pressure of $18 \mathrm{~mm}$ by applanation. A Laser vision test revealed a vision potential of $20 / 300$. The situation was managed conservatively, until the patient came back 3 months later with increasing pain and irritation in the eye. The basic situation had not changed much, but the intraocular pressure had increased to $25 \mathrm{~mm}$ on medication. Cyclocryothermy was used in eight applications without much success. Thus, another eight applications of cyclocryothermy were given 2 months later and resulted in control of the glaucoma. The eye was comfortable and did not have bullous keratopathy.

Increasing cataract in the left eye led to an atteimpt at surgical correction of the right eye. An 8-mm penetrating keratoplasty was done with local anesthesia on December 27, 1973 by Kent Bennet, M.D., a former staff member of this department. When the corneal button was removed, it was observed immediately, that its posterior surface was smooth dark brown. Lens remnants and scar tissue were found in the region of the pupil and were removed along with some vitreous. A clear view into posterior aspects of the eye during surgery revealed a smooth mound, and this was considered a choroidal detachment. The postoperative course was uncomplicated for a few years. On May 27, 1978, for example, vision in the right eye could be improved to 20/50 and the pressure was $11 \mathrm{~mm}$ by applanation. Later in the same month, however, corneal clouding developed and became worse progressively. A graft reaction was diagnosed. Superficial corneal vascularization and progressive scarring were observed and the patient has a vision of hand motion in 1 foot and a pressure of $8 \mathrm{~mm}$ when he was seen last in December 1980.

The corneal button obtained on December 27, 1973, measured $7 \mathrm{~mm}$ in diameter and was dark brown in back. It was cut in half for cross and flat sectioning. There was also a small piece of scar tissue with lens fragments. Sections showed the corneal epithelium to be almost totally absent, but the remaining portions were about normal. Bowman's membrane was continuous and very well preserved. The corneal stroma was somewhat irregular and exhibited only very occasional PMNs. There was no neovascularization. Descemet's membrane was very well preserved and exhibited no coarse wrinkling or signs of degeneration. The corneal endothelium was totally absent. It was replaced by a continuous layer of pigmented cells of a somewhat irregular and very beautiful pattern (Figs. 1-5). These cells had small pigment granules in their protoplasm; the density of the pigment varied from cell to cell. The impression was that the cells had formed a continuous layer, but accidental drying before fixation had caused separation with artificial spaces between the individual cells (Fig. 5). Most cells had long processes, but some were larger and more epitheloid (Figs. 4 and 5). In general, the smaller and most deeply pigmented cells had dense oval nuclei, while the larger and less pigmented cells had round nucleolated nuclei; Many of the larger cells had two or even three nuclei (Figs. 3-5). The cells formed a monolayer, but this was not perfect; cell processes were seen to cross over each other in many places (Figs. 2-5). The arrangement of the cells in some areas indicated the direction of growth by which these cells had extended onto the cornea (Figs. 3-5). The cells in their darkly pigmented and long-processed stages resembled uveal melanocytes. The larger cells with less pigment had clearly developed from the smaller cells, but they gave the impression of a different functional element and slightly resembled corneal endothelium (Figs. 4 and 5). The scar tissue removed from the pupil was partly covered with the same proliferating pigmented cells seen on the posterior corneal surface. 


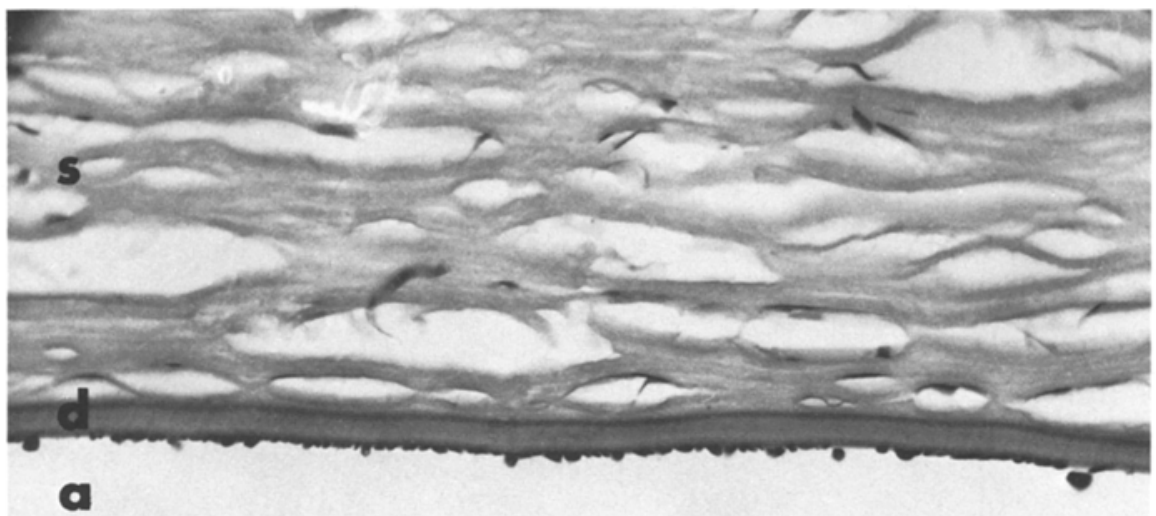

Fig. 1. Cross section of deep stroma (s), Descemet's membrane $(d)$, and layer of pigmented cells facing the anterior chamber $(a)$ in the present case. Paraffin section, H \& E stain, photomicrograph $\times 50$

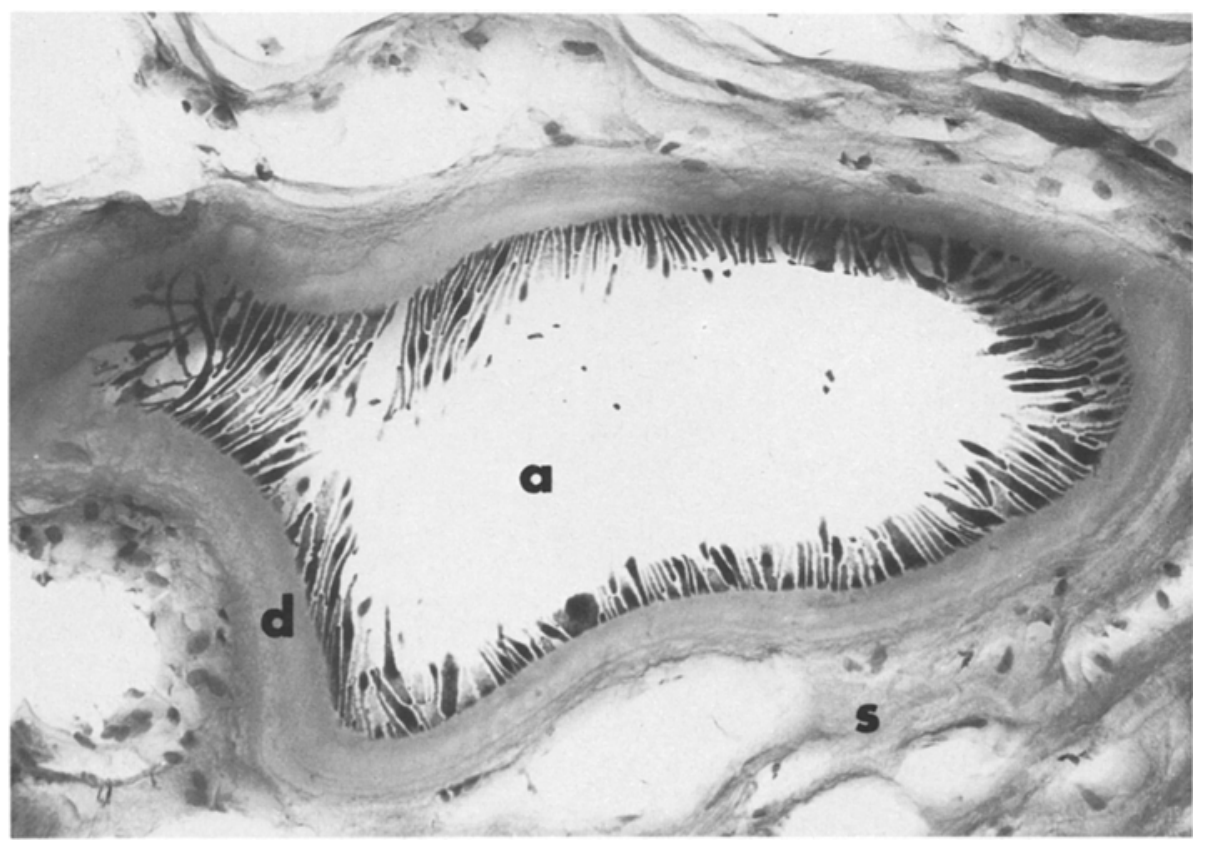

Fig. 2. Flat section through center of corneal button showing stroma $(s)$, Descemet's membrane (d), and a ring of pigmented cells on its posterior surface facing the anterior chamber $(a)$. The contrasting demonstration of the cells on Descemet's membrane is the result of their natural pigmentation. Paraffin section, H \& E stain, photomicrograph $\times 50$ 


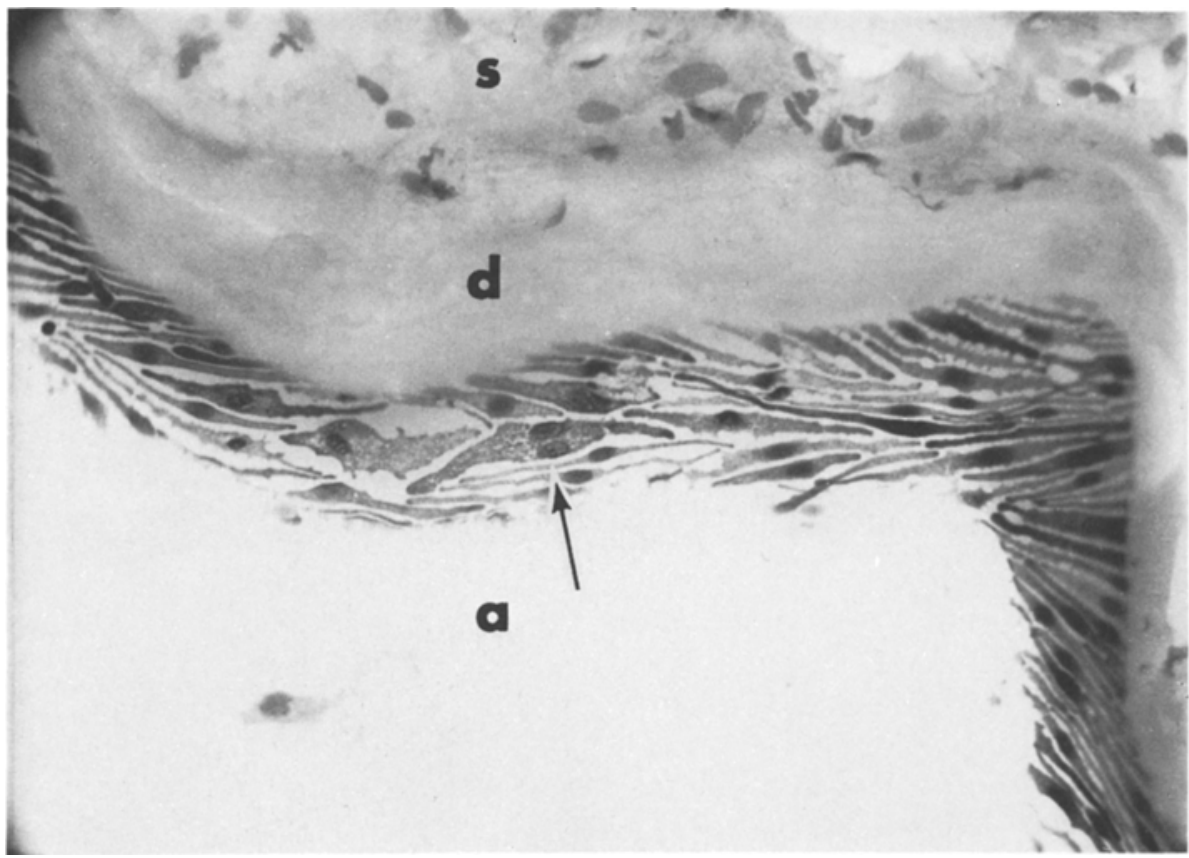

Fig. 3. Transitional section through stroma $(s)$ and Descemet's membrane $(d)$ show the pigmented cells facing the anterior chamber to be mostly spindle-shaped. Some of the larger cells (arrow) have less pigment and two nucleolated nuclei. Paraffin section, H \& E stain, photomicrograph $\times 100$

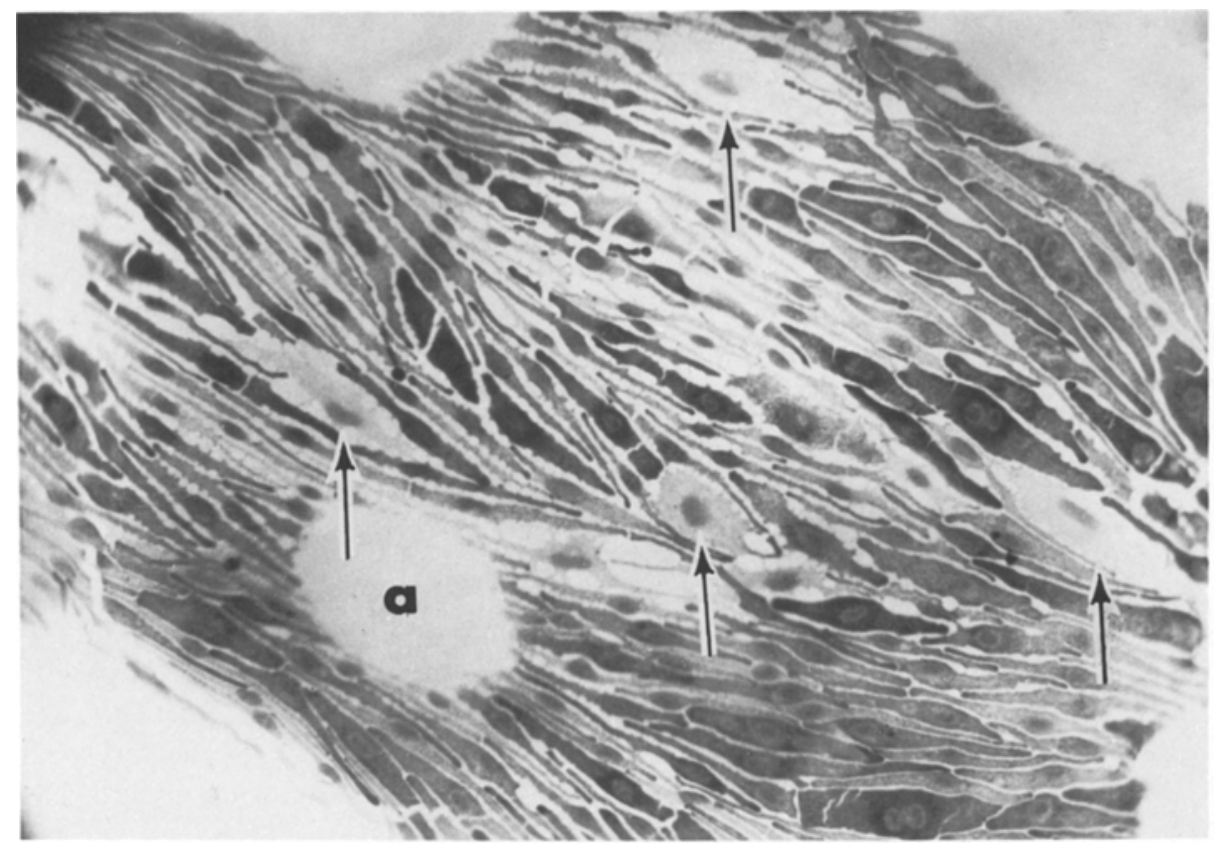

Fig. 4. Flat section of a sheet of pigmented cells on the cornea facing the anterior chamber $(a)$. Some of the larger cells have lost most of their pigment (arrows). All transitional stages of cells developing from the dark and slender to the large and light types are seen 


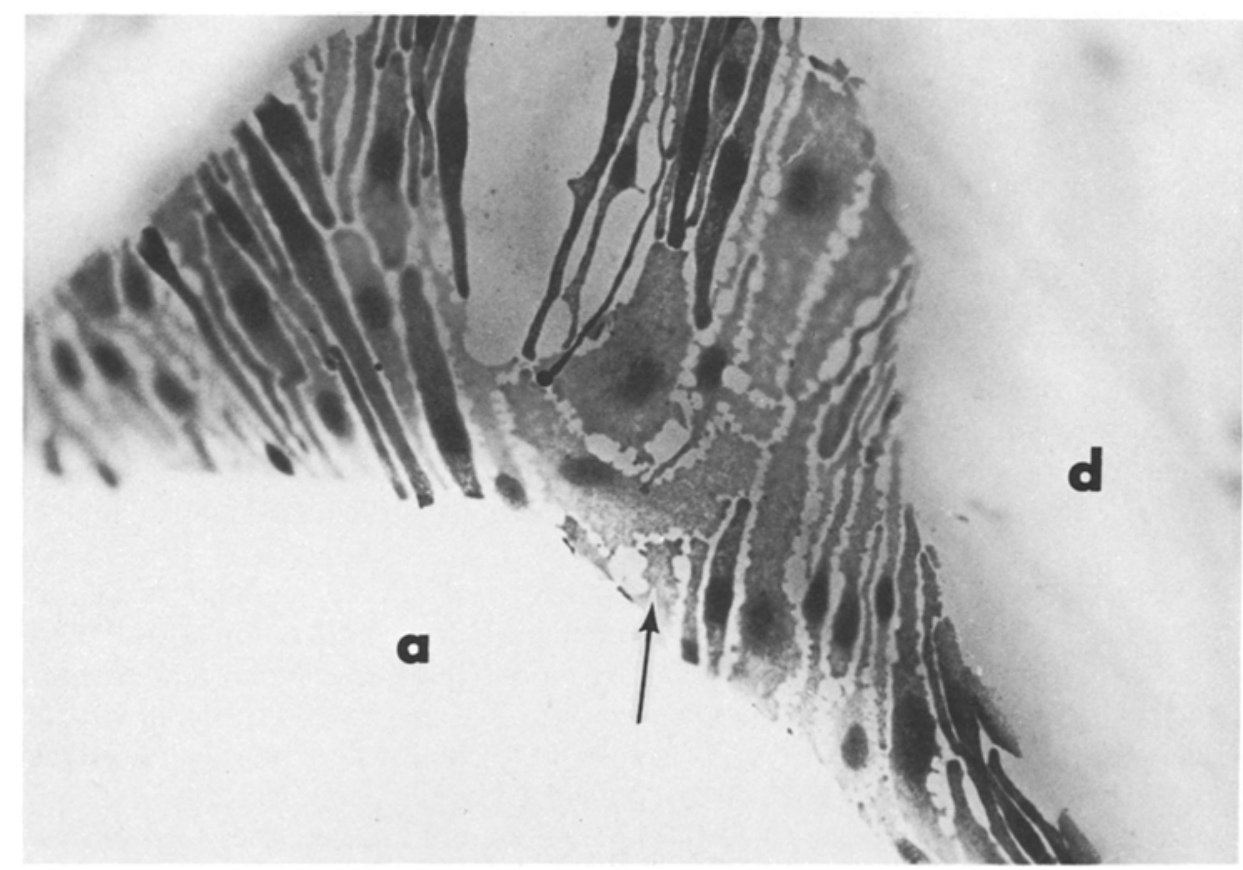

Fig. 5. High power view of transitional section from Descemet's membrane into anterior chamber (a). Some of the larger cells on Descemet's membrane resemble endothelial cells and do not contain much pigment (arrow). Crossing of cell processes over each other is seen in several places. Paraffin section, H \& E stain, photomicrograph $\times 250$

\section{Discussion}

A closed anterior chamber angle with touch of iris and cornea central to Schwalbe's line is well known to be a bridge for sheathlike proliferation of corneal endothelium onto the iris in young people. In cases of atrophy of this endothelium, however, the stream of cellular proliferation can go the other way. Melanocytes have been observed to extend onto the posterior corneal surface and form a monolayer of cells. Kaufer et al. (1967) have demonstrated this process in detail in nine cases. The association of this relatively rare occurrence with old trauma or surgery as well as with glaucoma has become obvious. Ueno et al. (1979) have shown in one case, furthermore, that proliferation of iris melanocytes can occur across the trabeculum of an open angle and cause glaucoma. Important details from these earlier studies of melanocytes on the posterior corneal surface are: a great tendency to proliferate, the ability to form a monolayer in the place of the corneal endothelium, and the capability of some of the proliferating melanocytes to lose much of their pigment production and remain clear. At least one surgeon believes, however, that the proliferating melanocytes were the main reason for obstruction of vision in one case (Bloomfield and Gray 1979).

The microscopic views in the present case show, first of all, that disease is not always an enemy of beauty. In addition, the observations in the present 
case add a number of important facts to earlier observations in cases of melanocyte proliferation on the posterior cornea. It can be emphasized that the melanocytes get along very well with Descemet's membrane, which looks continuous and very well preserved. This is in contrast to the condition of Descemet's membrane seen in cases with mesodermal retrocorneal membranes. Next to mesodermal retrocorneal membranes, Descemet's membrane tends to wrinkle, exhibits signs of degeneration, and may break down and elicit foreign body reaction or a more extensive granulomatous inflammation presumably due to autoimmune hypersensitivity (Wolter et al. 1971). Melanocytes on the posterior corneal surface are clearly able to form a layer of densely arranged cells in the absence of corneal neovascularization. This is not a perfect monolayer. Some cell processes cross each other, but an effective covering is achieved. Some of the cells, furthermore, contain only very little pigment and are almost clear.

Corneal edema is recognized histologically not simply by fluid spaces in the stroma since this often occurs as an artifact. Diffuse infiltration with PMNs and wrinkling of Descemet's membrane are more reliable signs of chronic corneal edema and are best seen in histological flat sections. Chronic edema in the deep layers, furthermore, typically results in breakdown of corneal lamellae as well as in neovascularization, of course. All these signs of corneal edema were absent in the present case. Descemet's membrane and the deep cornea were well preserved and appeared to have been doing relatively well with this layer of melanocytes in the place of the endothelium. Clinically, the cornea had a continuous epithelium without blisters. Could all this indicate a dehydrating activity of these melanocytes?

Further study of melanocytic monolayers in the place of corneal endothelium is indicated, in my opinion, with the thought to use these cells as a replacement in desperate situations. They can be obtained from the iris and are known to grow in tissue culture (Busacca 1952). The present case shows again that they appear to proliferative under conditions that result in endothelial atrophy. Their pigmentation may not be all that disturbing or they may be influenced to lose most of it. Some of the melanocytes on the cornea of this black patient had already lost almost all of their pigment granules. The fact that uveal melanocytes of adult eyes have the potential for a change into an endotheliumlike layer on the posterior cornea is truly remarkable - and this observation should be useful for future research.

It has to be emphasized that the flat sections in the present case (Figs. 4 and 5, for example) contain the whole thickness of the monolayer of melanocytes. The sections were not depigmented before the simple $\mathrm{H}$ and $\mathrm{E}$ staining. The amount of pigment present in some of the larger cells is less than what is seen in the endothelium in conditions of pigment dispersion or chronic iritis, for example. This amount of pigment may result in conditions of light screening similar to vision with sunglasses or stained contact lenses, but it will not cause blindness. An eye with a monolayer of somewhat depigmented melanocytes in the place of the endothelium could thus be expected to see, if the remainder of the eye is functioning. 


\section{References}

Bahn CF, MacCallum DK, Meyer RF, Lillie J, Martonyi CL (in print) Complications associated with cultured bovine corneal endothelial lined homografts in the cat. Invest Ophth

Kaufer G, Fine BS, Green WR, Zimmerman LE (1967) Retrocorneal pigmentation, Am J Ophthalmol 64:567-586

Ueno H, Green WR, Kenyon KR, Hoover RE (1979) Trabecular and retrocorneal melanocytes, Am J Ophthalmol 88:592-597

Bloomfield SE, Gray BF (1979) Corneal transplantation for endothelial pigmentation, Ann Ophthalmol 11:1783-1786

Wolter JR, Johnson FD, Meyer RF, Watters JA (1971) Acquired autosensitivity to degenerating Descemet's membrane in a case with anterior uveitis in the other eye, Am J Ophthalmol 72:782786

Busacca A (1952) Biomicroscopie et Histopathologie de L'Oeil, Grune and Stratton, New York, p 430

Received July 6, 1981 